\title{
APRESENTAÇÃO
}

\section{DOSSIÊ: HISTÓRIA DAS DOENÇAS E DA SAÚDE: EXPERIÊNCIAS E PERSPECTIVAS}

\section{Eliza Vianna* \\ Gabriel Lopes**}

É com muita alegria que apresentamos o dossiê História da Saúde e das Doenças: experiências e perspectivas, trazendo trabalhos que exploram temáticas variadas na área. Nas últimas décadas, cresceu consideravelmente a produção de pesquisas no âmbito da História das Doenças e da Saúde. As pesquisas sobre a história do conhecimento médico e científico, antes restritas ao esforço de memória dos profissionais da área, foram incorporados ao ofício de historiadores(as), abrindo um leque infinito de análises sobre a institucionalização de saberes e práticas; a ancoragem social e histórica do conhecimento médico-científico; as políticas públicas de saúde; a experiência do adoecimento etc.

Abrindo o dossiê, temos o artigo "A hora da educação sexual": práticas educativas do sexo, da saúde e das doenças em conselhos impressos (Paraíba, década de 1930)" em que Azemar dos Santos Soares Júnior e Rafael Nóbrega Araújo abordam os discursos médico-pedagógicos publicados na imprensa paraibana pelo Círculo Brasileiro de Educação Sexual (CBES), escritos pelo médico, autoproclamado sexólogo, José de Albuquerque sobre educação sexual ao longo da década de 1930. Em tais publicações encontravam-se informações e conselhos a respeito da questão sexual e da sexualidade voltados para a divulgação das ideias sobre educação sexual e sexologia fomentadas pelo referido médico com vistas a educar o público leitor das referidas publicações. Os autores compreendem que tais discursos configuravam como práticas educativas a partir do momento que visavam incutir nos leitores daqueles jornais hábitos e pensamentos higiênicos pautados pelo saber médico a respeito do sexo e da sexualidade.

Na sequência, os pesquisadores Vanessa Lana e Luiz Antonio Teixeira nos apresentam uma análise do pensamento médico sobre o câncer de mama em seu artigo intitulado "O câncer de mama nas páginas dos Anais Brasileiros de Ginecologia”. O artigo analisa o percurso do pensamento médico na configuração do câncer de mama como doença e a organização de conhecimentos e práticas sobre a mesma no Brasil tendo como marcos o início das discussões e ações em relação aos cânceres ginecológicos, na década de 1930, e a introdução do mamógrafo como instrumento de diagnóstico do câncer de mama no país, nos anos 1970, que impactou diretamente as práticas de controle da doença.

O terceiro artigo, intitulado Entre Cobras e Plantas, muitas Glândulas: A produção de hormônios e assistência às doenças endocrinológicas no Instituto Butantan-1917-1945, aborda a elaboração de produtos

\footnotetext{
* Doutora em História das Ciências e da Saúde pelo Programa de Pós-Graduação em História das Ciências e da Saúde (PPGHCS/COC/FIOCRUZ - 2018). Professora de História no Instituto Federal de Alagoas (IFAL). E-mail: eliza.vianna@gmail.com

** Doutorado em História das Ciências e da Saúde pela Casa de Oswaldo Cruz - FIOCRUZ (2016) com período de doutorado sanduíche no Department of the History of Medicine na Johns Hopkins University (2014/2015). Vencedor do primeiro lugar do Prêmio Oswaldo Cruz de Teses (Ciências Humanas e Sociais) em 2017. E-mail: gabriel.lopes.mailbox@gmail.com
} 
hormonais e assistência aos portadores de disfunções glandulares no Instituto Butantan, na primeira metade do século XX. Nele, Rodrigo Ramos Lima analisou relatórios administrativos, bulas médicas, periódicos científicos, acervo fotográfico e depoimentos de cientistas que atuaram na instituição. Seu principal objetivo foi apresentar a atuação do Instituto Butantan no tratamento das disfunções hormonais no contexto de emergência das doenças glandulares como problema de saúde pública no Brasil, na primeira metade do século XX.

A pandemia de gripe espanhola, que se alastrou no Brasil em 1918 deixando mais de 35 mil mortos, é um tema pouco abordado fora dos grandes centros urbanos da época. Érico Silva Alves Muniz e Silviane de Carvalho Ferias em $A$ influenza entre nós: $A$ interiorização da gripe espanhola na Amazônia e a chegada da doença a Bragança (PA) (1918) a partir de uma revisão historiográfica, abordam enquadramentos possíveis do processo de interiorização da gripe espanhola. Ao analisar as notícias divulgadas no jornal A Cidade sobre a epidemia em Bragança (PA), os autores mostram a importância do estudo da história local para compor especificidades de um quadro mais amplo que foi a passagem da gripe espanhola no Brasil, destacando alguns condicionantes tanto sociais quanto biológicos da doença.

Temos certeza de que a leitura será proveitosa e que os trabalhos em muito contribuem para a pesquisa no Brasil. 